\section{Fc-engineering significantly improves the recruitment of immune effector cells by anti-ICAM-1 antibody MSH-TP15 for myeloma therapy}

\author{
Katja Klausz, ${ }^{1}$ Michael Cieker, ${ }^{1}$ Christian Kellner, ${ }^{2}$ Thies Rösner, ${ }^{1}$ Anna Otte, ${ }^{1}$ \\ Steffen Krohn, ${ }^{1}$ Anja Lux, ${ }^{3}$ Falk Nimmerjahn, ${ }^{3}$ Thomas Valerius, ${ }^{1}$ \\ Martin Gramatzki ${ }^{1}$ and Matthias Peipp ${ }^{1}$ \\ ${ }^{1}$ Division of Stem Cell Transplantation and Immunotherapy, Department of Internal \\ Medicine II, University Hospital Schleswig-Holstein and Christian-Albrechts-University, \\ Kiel; ${ }^{2}$ Department of Transfusion Medicine, Cell Therapeutics and Hemostaseology, \\ University Hospital, LMU Munich, Munich and ${ }^{3}$ Institute of Genetics, Department of \\ Biology, University of Erlangen-Nürnberg, Erlangen, Germany
}

\section{ABSTRACT}

$\longrightarrow$ espite several therapeutic advances, patients with multiple myeloma (MM) require additional treatment options since no curative therapy exists yet. In search of a novel therapeutic antibody, we previously applied phage display with myeloma cell screening and developed TP15, a single-chain fragment variable targeting intercellular adhesion molecule 1 (ICAM-1/CD54). In order to more precisely evaluate the antibody's modes of action, fully human immunoglobulin G1 antibody variants were generated bearing the wild-type (MSH-TP15) or mutated fragment crystallizable (Fc-engineered [Fc-eng.]) region to either enhance (MSH-TP15 Fc-eng.) or prevent (MSH-TP15 Fc knockout [Fc k.o.]) Fcy receptor binding. Especially MSH-TP15 Fc-eng. induced significant antibody-dependent cell-mediated cytotoxicity against malignant plasma cells by recruiting natural killer cells and engaged macrophages for antibody-dependent cellular phagocytosis of tumor cells. Binding studies with truncated ICAM-1 demonstrated MSHTP15 binding to ICAM-1 domain 1-2. Importantly, MSH-TP15 and MSHTP15 Fc-eng. both prevented myeloma cell engraftment and significantly prolonged survival of mice in an intraperitoneal xenograft model. In the subcutaneous model MSH-TP15 Fc-eng. was superior to MSH-TP15, whereas MSH-TP15 Fc k.o. was not effective in either of the models - reflecting the importance of Fc-dependent mechanisms of action also in vivo. The efficient recruitment of immune cells and the observed anti-tumor activity of the Fcengineered MSH-TP15 antibody hold significant potential for myeloma immunotherapy.

\section{Introduction}

With approval of the monoclonal antibodies $(\mathrm{mAb})$ daratumumab and elotuzum$\mathrm{ab}$ in 2015, antibody-based immunotherapy has entered clinical practice for multiple myeloma (MM) patients. While both mAb show therapeutic activity in combination with standard treatment regimens, only daratumumab has significant singleagent activity and is additionally approved as front-line therapy. Increased survival rates and good tolerability are achieved with both $\mathrm{mAb}$, but still not all patients benefit and first drug resistances have been reported. ${ }^{1,2}$ Thus, there is still a high unmet medical need for myeloma patients.

For homing and growth of malignant plasma cells in the bone marrow (BM), adhesion molecules are of significant importance and 'hiding' tumor cells in the BM are believed to induce relapse in myeloma patients. ${ }^{3,4}$ Therefore, targeting the BM microenvironment and adhesion molecules might be explicitly reasonable for MM therapy. ${ }^{5}$ For instance, intercellular adhesion molecule-1 (ICAM-1/CD54) is reported to be highly expressed on malignant plasma cells and not down-regulated under MM therapy. ${ }^{6}$ Of note, significantly higher levels of ICAM-1 are expressed on
Ferrata Storti Foundation

Haematologica 2021

Volume 106(7):1857-1866

\section{Correspondence:}

MATTHIAS PEIPP

m.peipp@med2.uni-kiel.de

Received: March 11, 2020.

Accepted: May 28, 2020.

Pre-published: June 4, 2020.

https://doi.org/10.3324/haematol.2020.251371

(C)2021 Ferrata Storti Foundation

Material published in Haematologica is covered by copyright. All rights are reserved to the Ferrata Storti Foundation. Use of published material is allowed under the following terms and conditions:

https://creativecommons.org/licenses/by-nc/4.0/legalcode. Copies of published material are allowed for personal or internal use. Sharing published material for non-commercial purposes is subject to the following conditions:

https://creativecommons.org/licenses/by-nc/4.0/legalcode, sect. 3. Reproducing and sharing published material for commercial purposes is not allowed without permission in writing from the publisher. 
malignant plasma cells from MM patients treated with chemotherapy and especially in tumors with a multi-drug resistance phenotype.? This is in line with the observation that adhesion molecules such as ICAM-1 are involved in macrophage-induced drug resistance and tumor escape in myeloma. ${ }^{8}$ In contrast, expression of ICAM-1 in healthy tissue, e.g., on endothelial cells and leukocytes, is constitutively low and increases only after stimulation with cytokines, i.e., interferon (IFN)- $\gamma$ or interleukin (IL)-1 $\beta$, which are up-regulated and released during inflammation and infection. ${ }^{9}$ Clinical trials with anti-ICAM-1 antibodies in patients with rheumatoid arthritis, renal transplants, stroke and myeloma proved safety and tolerability, but often lacked significant activity. ${ }^{10-13}$

Most therapeutic antibodies used for cancer immunotherapy are of immunoglobulin (Ig) G1 isotype and exert their anti-tumor activity via antigen-binding fragment (Fab)- and/or fragment crystallizable (Fc)-mediated effector functions directly through antigen binding and/or interactions with the immune system. ${ }^{14}$ The Fc-mediated effector functions encompass antibodydependent cell-mediated cytotoxicity (ADCC), antibodydependent cellular phagocytosis (ADCP) and complement-dependent cytotoxicity (CDC). Over the years many efforts have been made to improve Fc-mediated effector functions of $\mathrm{mAb}$ to increase their cytotoxic and therapeutic activity by Fc glyco- and Fc protein-engineering techniques. Fc protein-engineering approaches make use of specific amino acid substitutions in the Fcy receptors $(\mathrm{F} c \gamma \mathrm{R})$ and $\mathrm{C} 1 \mathrm{q}$ binding interfaces of a therapeutic antibody to specifically improve ADCC, ADCP and/or CDC activity.15-19 Lazar and colleagues identified the S239D and I332E (DE) mutations in the CH2 domain of IgG1 antibodies, which markedly enhanced binding to the activating FcrRIIIa/CD16a and ADCC activity of a variety of therapeutic IgG1 antibodies. ${ }^{15}$ The DE mutations have been applied to generate an Fc-engineered (Fc-eng.) CD19 antibody that demonstrates promising therapeutic activity in clinical trials for relapsed/refractory B-cell non-Hodgkin lymphoma. ${ }^{20}$ Margetuximab, an Fc-optimized anti-HER2 antibody with reduced binding to FcrRIIb/CD32b and enhanced affinity for FcyRIIIa/CD16a, ${ }^{21}$ is currently evaluated in a phase III study for breast cancer and also highlights the potential of Fc-engineering as a strategy to improve antibodies for cancer immunotherapy.

Here, we applied Fc-engineering to MSH-TP15, a novel, fully human anti-ICAM-1 IgG1 antibody whose variable regions are derived from TP15-Fc originally isolated by phage display and screening of myeloma cells. ${ }^{22} \mathrm{Fab}$ - and Fc-mediated effector functions of MSH-TP15 were analyzed by comparing three antibody variants that differed in their affinity for Fc $\gamma$ R's on immune cells. Antigen binding, direct anti-tumor effects and immune cell recruitment for tumor cell lysis by the MSH-TP15 antibody variants were tested in vitro and in vivo against myeloma cells.

\section{Methods}

\section{Cell separation}

Mononuclear cells from peripheral blood (PBMC), pleural effusion $(\mathrm{PE})$ and $\mathrm{BM}$ of myeloma patients and healthy donors were isolated as previously described. ${ }^{23}$ Samples were taken after receiving donors' written informed consents. Experiments were in accordance with the Declaration of Helsinki and approved by the
Ethics Committee of the Christian-Albrechts-University, Kiel, Germany (D442/10).

\section{Cell lines}

Ramos, CHO-K1, L363 and U266 were obtained from DSMZ (Braunschweig, Germany), Lenti-X 293T were purchased from Takara Bio (Göteborg, Sweden), MM1.S, Raji CS and CHOFc $\gamma$ RIIa-131H were gifts from YT Tai (Boston, MA, USA), MJ Glennie (Southampton, UK), and F Nimmerjahn (Erlangen, Germany), ${ }^{24}$ respectively, and cultured as recommended. INA-6, INA-6.Tu1 and BHK-FcyRIIIa-158V were established in our laboratory and cultured as previously described. ${ }^{25,26}$

\section{Production of MSH-TP15 antibody variants}

Variable light $(\mathrm{VL})$ and heavy chain $(\mathrm{VH})$ sequences derived from phage PIII- $15^{22}$ and BI-505,27 were cloned into modified pSecTag2/HygroC vectors harboring sequences for the constant region of the human kappa light chain (LC) or either wild-type (wt) or mutated human IgG1 heavy chain (HC). ${ }^{28}$ Antibodies were termed MSH-TP15 (wt IgG1), MSH-TP15 Fc-engineered (Fc-eng.) and MSH-TP15 Fc knockout (Fc k.o.) and produced as described in the Online Supplementary Appendix.

\section{Flow cytometric analyses}

Immunofluorescence analyses to investigate $\mathrm{mAb}$ binding, induction of programmed cell death (PCD) and ADCP were performed on a Navios flow cytometer and analyzed with Kaluza software (Beckman Coulter). For details please refer to the Online Supplementary Appendix.

\section{Co-culture experiments}

BM stromal cells (BMSC) were isolated from MM patient BM aspirates and used for co-culture experiments with INA- 6 cells as previously described. ${ }^{29}$

\section{Cytotoxicity assays}

ADCC activity was analyzed in 3 hour $(\mathrm{h}){ }^{51} \mathrm{Cr}$ release assays using PBMC and natural killer (NK) cells at E:T ratios of 80:1 and $10: 1$, respectively, as previously described. ${ }^{23}$

\section{Live cell imaging}

INA-6 killing was analyzed over $24 \mathrm{~h}$ with IncuCyte caspase$3 / 7$ reagent $(250 \mathrm{nM})$ in the presence or absence of NK cells (E:T ratio $10: 1)$ and $20 \mu \mathrm{g} / \mathrm{mL}$ of the indicated antibodies with IncuCyte live cell imaging (Essen Bioscience). Green cell counts per image were analyzed with Zoom2016A software.

\section{Animal experiments}

All animal experiments were performed according to the guidelines of the Christian-Albrechts-University Kiel along with the German Animal Protection Law. For both models 7-8 week-old female SCID/beige mice (Charles River, Sulzfeld, Germany) and red fluorescent protein-expressing INA-6.Tu1 cells (INA6.Tu1_red; unpublished) were used. In the intraperitoneal (i.p.) model, ten mice/group were injected with $20 \times 10^{6}$ INA-6.Tu1_red cells $48 \mathrm{~h}$ prior start of twice weekly i.p. treatment with $\mathrm{mAb}$ (initial doses $10 \mathrm{mg} / \mathrm{kg}$ followed by six doses of $5 \mathrm{mg} / \mathrm{kg} \mathrm{mAb} / \mathrm{ani}-$ mal) or vehicle control. In the established tumor model $5 \times 10^{6}$ INA6.Tu1_red cells were subcutaneously (s.c.) injected into the right hind flank of five mice/group. At day 10, i.p. treatment with five doses of 10,1 or $0.1 \mathrm{mg} / \mathrm{kg} \mathrm{mAb} /$ mouse twice weekly was started. Tumor growth was measured by caliper and volume was calculated: (length $\mathrm{x}$ width $\left.{ }^{2}\right) / 2$. Human IL-6 receptor was analyzed with CD126 enzyme-linked immunosorbent assay (ELISA) kit (Diaclone, Besançon, France). 
A

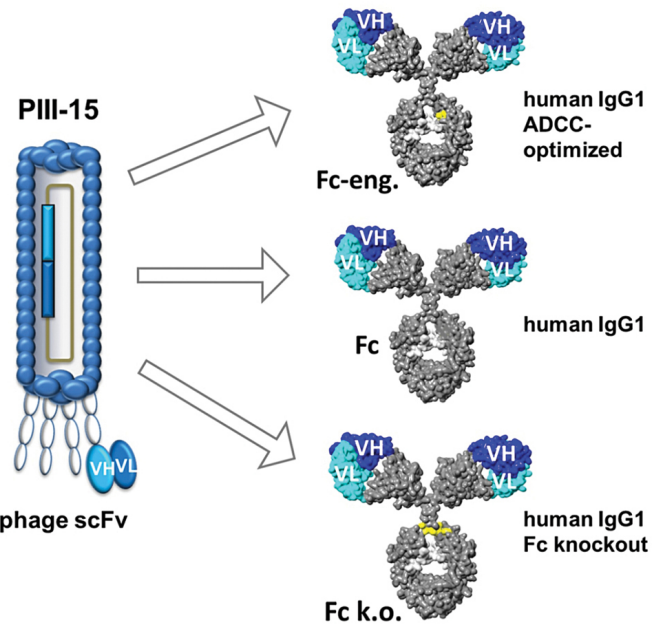

B

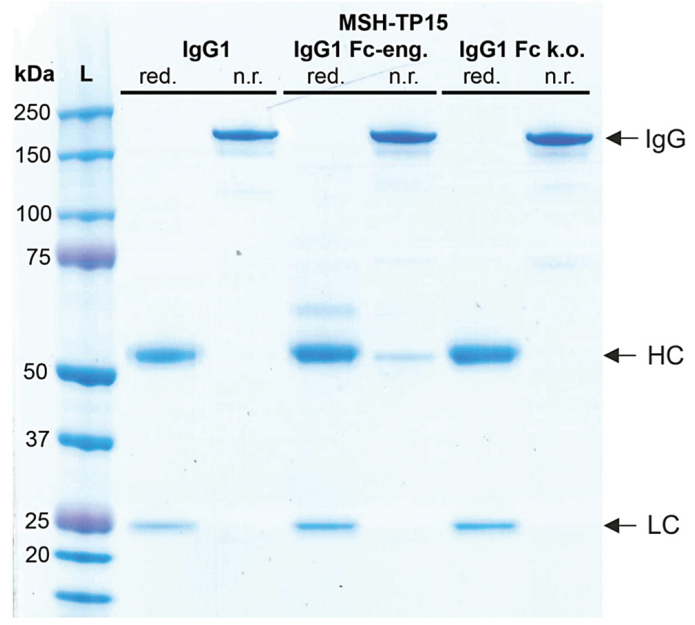

C

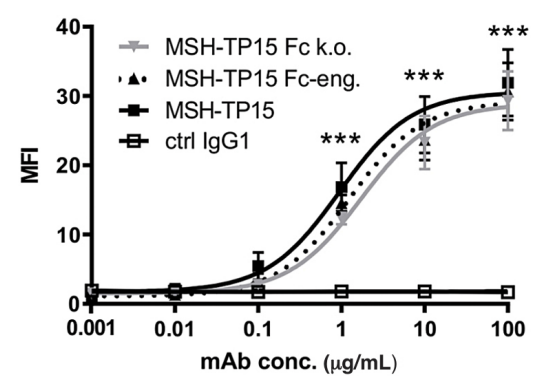

D

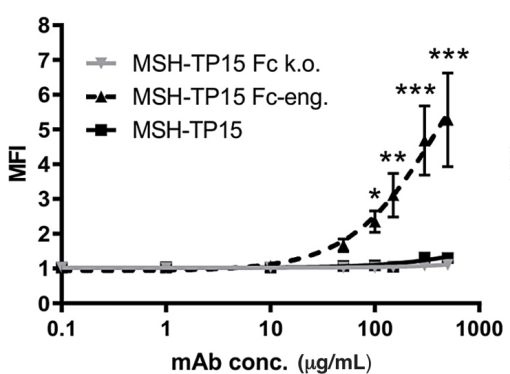

E
Fc $\gamma$ RIlla-158V

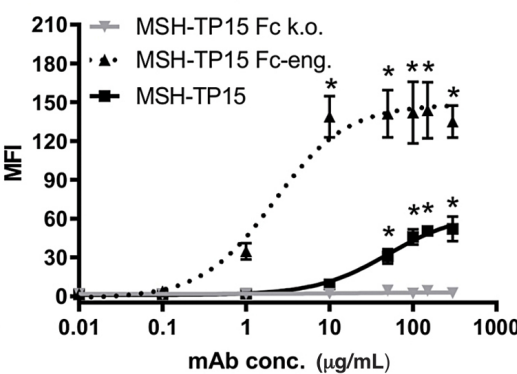

Figure 1. Generation and binding characteristics of MSH-TP15 antibody variants. (A) The variable heavy (VH) (dark blue) and variable light (VL) (light blue) sin-glechain fragment variable (scFv) sequences of phage antibody PIII-15 were used to generate three human immunoglobuin (Ig) G1 MSH-TP15 monoclonal antibody $(\mathrm{mAb})$ variants carrying either a wild-type (middle), a protein-engineered (Fc-eng.; top) or a knockout (k.o.; bottom) fragment crystallizable (Fc)-domain. Mutations in the constant region (grey) of the heavy chain (HC) are depicted in yellow, glycosylation is shown in light grey. (B) Purity and molecular masses of the produced antibodies was analyzed by sodium dodecyl sulfate polyacrylamide-based discontinuous gel electrophoresis (SDS-PAGE) and Coomassie staining under reducing (red.) and non-reducing (n.r.) conditions. ADCC: antibody-dependent cell-mediated cytotoxicity; L: molecular mass ladder; LC: light chain. (C) Intercellular adhesion molecule-1 (ICAM-1) binding was measured by flow cytometry using L363 myeloma cells and increasing antibody concentrations. CD20 antibody rituximab served as control (ctrl IgG1). $* * * P<0.001 \mathrm{MSH}-\mathrm{TP} 15 \mathrm{mAb}$ vs. ctrl IgG1. (D) Binding to human Fcy receptor (FcyR) was analyzed with $\mathrm{CHO}$ cells expressing human FcyRlla-131H or (E) BHK cells expressing either the low (FcyRIIla-158F) or the high affinity (FcyRllla-158V) allelic form of human CD16a. *P<0.05 MSH-TP15/MSH-TP15 Fc-eng. vs. MSH-TP15 Fc k.o.; MFI: mean fluorescence intensity. Data represent mean values \pm standard error of the mean of three independent experiments.

\section{Data processing and statistical analyses}

Data were statistically analyzed with GraphPad Prism Software using appropriate tests (San Diego, CA, USA). Significance was accepted with $P<0.05$.

\section{Results}

\section{Generation of MSH-TP15 IgG1 monoclonal antibodies} with different $\mathbf{F c} \gamma \mathbf{R}$ binding properties

$\mathrm{VL}$ and $\mathrm{VH}$ sequences of scFv-Fc antibody PIII-15, previously selected by phage display and panning with human myeloma cell lines, ${ }^{22}$ were used to generate three fully human IgG1א antibody variants. Compared to the wt IgG1 MSH-TP15, the Fc-optimized MSH-TP15 Fc-eng. and the Fc k.o. variant MSH-TP15 Fc k.o. were designed to display either enhanced FcyRIIa or FcyRIIla binding to improve effector cell activation while retaining wt CDC activity or being incapable to mediate CDC and ADCC and therefore exclusively rely on Fab-mediated effector functions (Figure 1A). All proteins were produced in LentiX 293-T cells. Antibody preparations were highly pure and LC appeared at the calculated molecular masses of $25 \mathrm{kDa}$ under reducing conditions. The slightly altered migration of the calculated $50 \mathrm{kDa} \mathrm{HC}$ and $150 \mathrm{kDa} \operatorname{IgG} 1$ antibodies that were observed under reducing and nonreducing conditions is most likely due to glycosylation (Figure 1B). Importantly, the three MSH-TP15 mAb showed almost identical, concentration-dependent binding to ICAM-1 with $\mathrm{EC}_{50}$ values in the low nanomolar (nM) range, but exerted significant differences in their FcyRIIa and FcyRIIIa binding (Figure 1C to E). As intended, the MSH-TP15 Fc k.o. did not bind to these FcyR on stable transfected cells, while binding of MSH-TP15 Fceng. was significantly enhanced for both FcrR compared to wt MSH-TP15 IgG1 (Figure 1D and E). Thus, these results confirmed the expected differences of the three antibody variants.

\section{MSH-TP15 binds domain 1 of human ICAM-1}

In order to proof that by converting the scFv to a Fab fragment, epitope specificity was not altered, L363 cells were pre-incubated with an excess of TP-15-Fc (scFv-Fc antibody) prior to staining with Alexa Fluor 755-labeled MSH-TP15 IgG1. Importantly, MSH-TP15 binding was completely inhibited indicating the same ICAM-1 binding epitope (Figure 2A). In order to more precisely localize the binding region of MSH-TP15, truncated ICAM-1 variants 
A

TP15-Fc

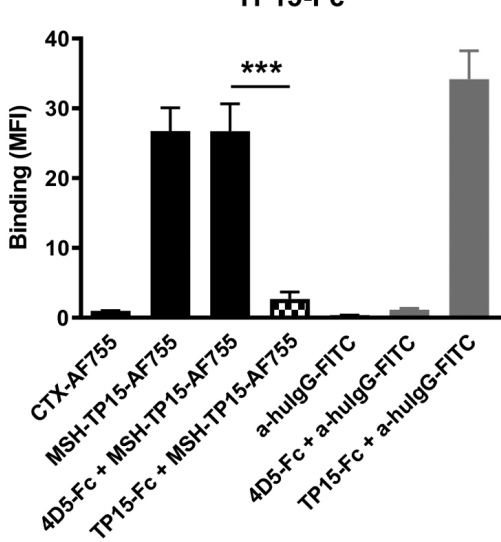

B
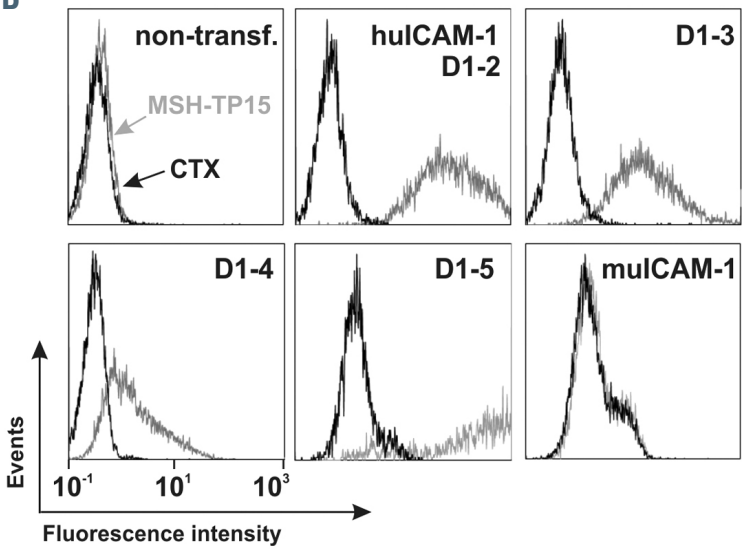

C
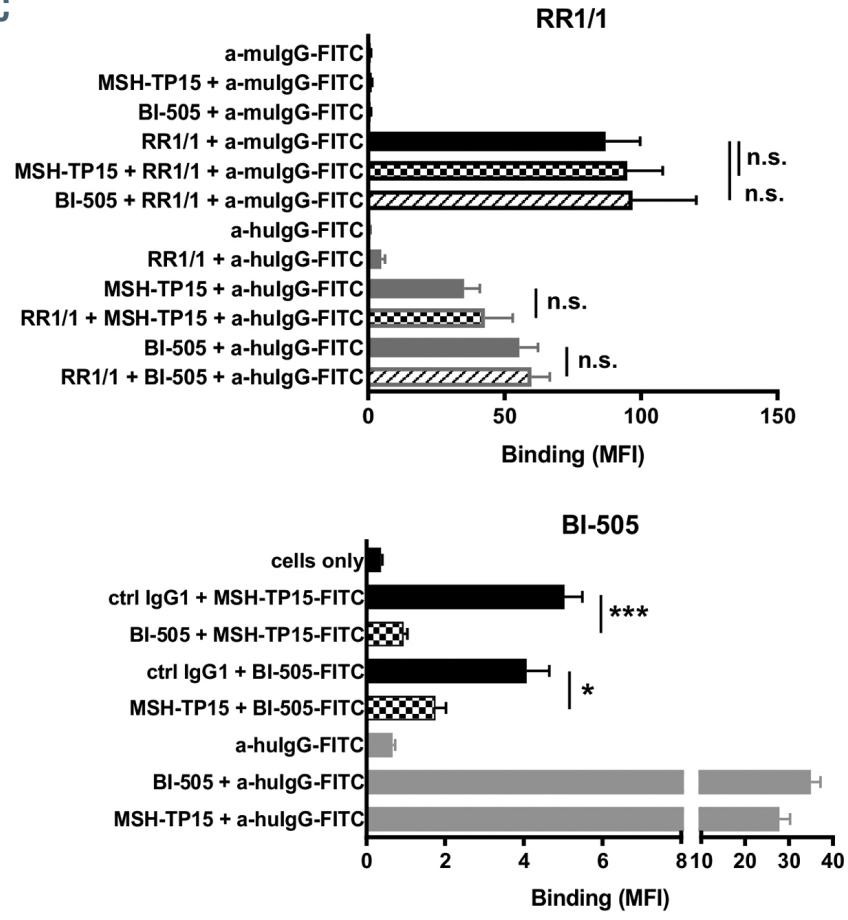
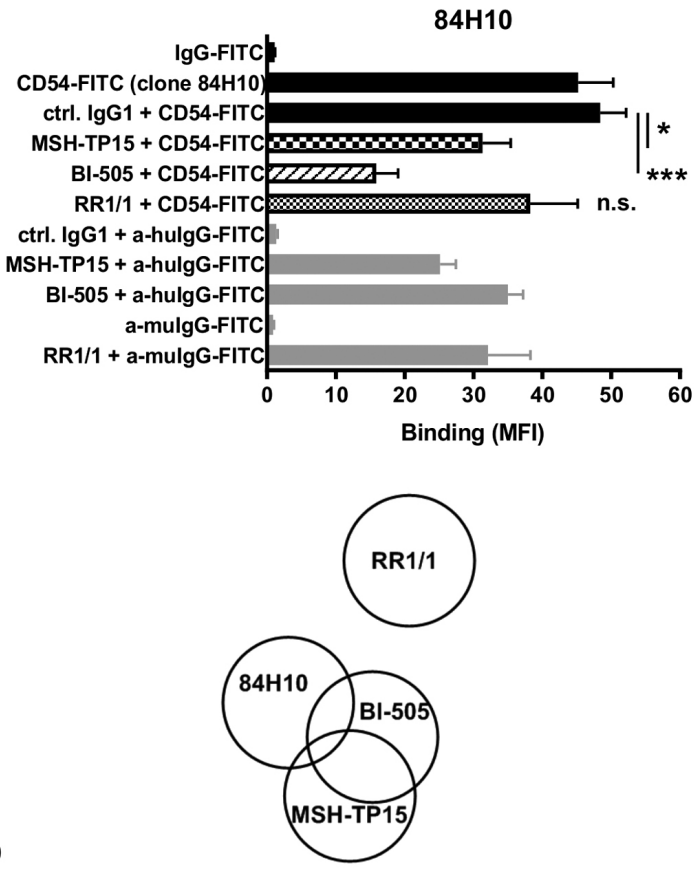

Figure 2. MSH-TP15 binds human ICAM-1 domain 1-2 and partly shares an epitope with CD54 antibodies BI-505 and 84H10. (A) In order to proof that binding specificity is retained by conversion of the single-chain fragment variable (scFv) to the antigen-binding fragment (Fab) containing antibody, cross-blocking studies with TP15-Fc and MSH-TP15 antibodies were performed on L363 cells. Pre-incubation with $500 \mu \mathrm{g} / \mathrm{mL}$ TP15-Fc, but not with the control molecule 4D5-Fc, significantly prevented binding of Alexa Fluor 755 (AF755)-labeled MSH-TP15 (checked bar) measured by flow cytometry. Identically labeled cetuximab (CTX-AF755) served as negative control. Binding of TP15-FC and 4D5-Fc were detected with FITC-labeled anti-human immunoglobulin (Ig) G antibody (grey bars). (B) Antibody binding to human intercellular adhesion molecule-1 (hulCAM-1) or mouse ICAM-1 (mulCAM-1) was analyzed by flow cytometry. Transiently transfected CHO-K1 cells expressing myc-tagged full length or truncated human ICAM-1 domains (D) D1-2 to D1-5 were stained with mouse anti-myc antibody and detected with a FITC-labeled anti-mouse secondary antibody. Histograms show binding of MSH-TP15-AF755 (grey) and CTX-AF755 (black) on ICAM-1 expressing CHO-K1 cells. Non-transfected (non-transf.) cells served as control. (C) Cross-blocking experiments with MSH-TP15 and ICAM-1 antibodies RR1/1, 84H10 and BI-505 were performed by flow cytometry on L363 cells with directly labeled antibodies or species specific anti-human or anti-mouse IgG secondary antibody as indicated in the graphs. All graphs show mean values \pm standard error of the mean of a minimum of three independent experiments. MFI: mean fluorescence intensity. Controls are shown in grey, cross-blocking in patterned bars. Statistics were calculated vs. pre-incubation with control lgG1 (ctrl lgG1) or binding of antibody without blocking (black bars). $* * * P<0.001, * * P<0.01$, $\star P<0.05$, n.s: not significant. Drawing summarizes the results and visualizes the overlapping epitopes of MSH-TP15, BI-505 and clone $84 \mathrm{H} 10$.

were cloned for cell surface expression on CHO-K1 cells (Online Supplementary Figure S1). Flow cytometric analyses revealed that for binding of MSH-TP15 at least ICAM-1 domain (D) 1-2 needed to be present. No binding to mouse ICAM-1 was observed (Figure 2B). For unknown reasons isolated expression of D1 was not possible. Therefore, we performed cross-blocking experiments with MSH-TP15 and the anti-human ICAM-1 mAb BI505, 84H10 and RR1/1, both known to bind human ICAM-1 D1. ${ }^{30}$ As shown in Figure 2C, addition of MSH-
TP15, BI-505 and 84H10 cross-blocked individual binding - suggesting that they bound to neighboring, overlapping, or even identical epitopes. This was especially observed for BI-505 and MSH-TP15 (Figure 2C). In contrast, RR1/1 binding was not cross-blocked by MSH-TP15, BI-505 or $84 \mathrm{H} 10$. This indicates a unique binding site for RR1/1, which was described to inhibit lymphocyte function-associated antigen-1 (LFA-1) ligand binding to ICAM-1 D1. ${ }^{31}$ In line with this, MSH-TP15 had no impact on LFA-1-ICAM1 interaction (data not shown). 
A

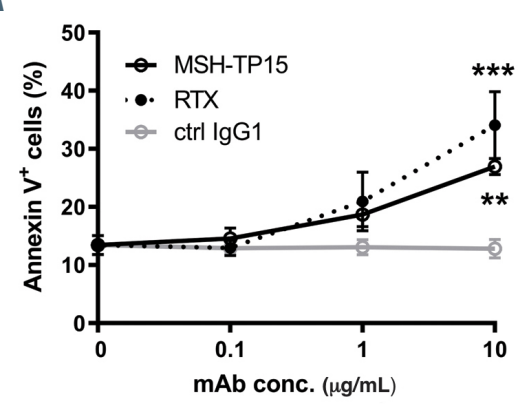

C

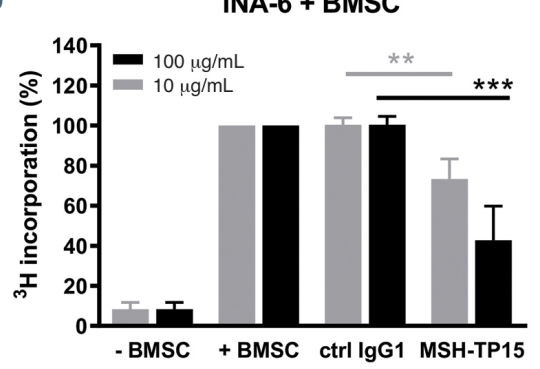

B
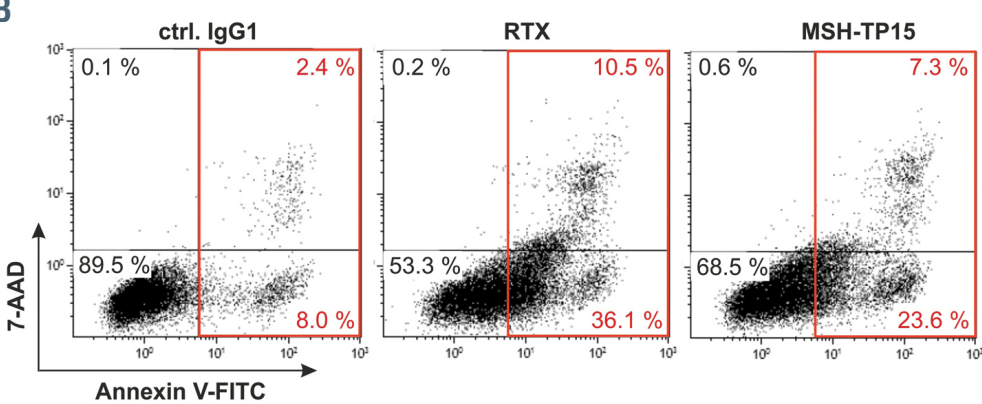

BMSC

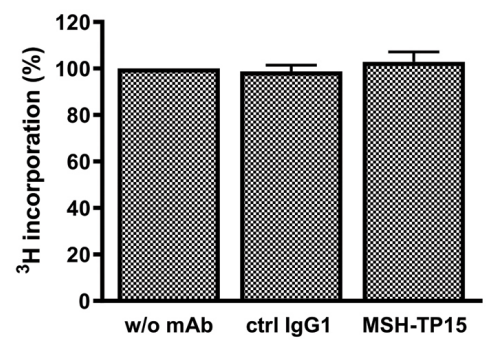

Figure 3. MSH-TP15 induces apoptosis of lymphoma cells after cross-linking on cell surface and inhibits myeloma growth in the presence of bone marrow stromal cells. (A) Induction of apoptosis was tested with Ramos lymphoma cells. After 6 -hour incubation with the indicated antibody and 10 ug/mL anti-human fragment crystallizable $\gamma(\mathrm{Fc} \gamma)$ cross-linking antibody AV-FITC and 7-AAD positive cells were detected by flow cytometry. Rituximab (RTX) served as positive, a control immunoglobulin (Ig) G1 (ctrl IgG1) as negative control. Mean percentage \pm standard error of the mean of four independent experiments is shown. (B) Results of one exemplified experiment with $10 \mathrm{ug} / \mathrm{mL}$ antibodies. AV-FITC-positive cells are marked in red boxes. (C) Growth inhibition of INA-6 myeloma cells was measured in the presence of bone marrow stromal cells (+BMSC) or absence of BMSC (-BMSC). MSH-TP15 and control lgG1 (ctrl lgG1) were used at $10 \mu \mathrm{g} / \mathrm{mL}$ (grey bars) or $100 \mu \mathrm{g} / \mathrm{mL}$ (black bars). Direct inhibitory effects on BMSC were not detected $(100 \mu \mathrm{g} / \mathrm{mL}$ monoclonal antibody [mAb]; right graph). w/o: without; ctrl: control. Experiments were performed four times in triplicates. Graphs show mean values \pm standard error of the mean. $* * * P<0.001, * * P<0.01$.

Table 1. $\mathrm{EC}_{50}$ values achieved by MSH-TP15 Fc-Fc-engineered in antibody-dependent cell-mediated cytotoxicity experiments with peripheral blood mononuclear cells

$\begin{array}{lcccc}\text { Cell line } & \text { TNA-6 } & \text { I363 } & \text { MIMA.S } & \text { U266 } \\ \mathrm{EC}_{50}(\mathrm{nM}) & 0.36(0.07-1.97)^{1} & 2.59(0.87-7.77)^{1} & 1.82(0.63-5.26)^{1} & 3.77(0.83-17.2)^{1}\end{array}$

${ }^{1} 95 \%$ CI Confidence Interval, sigmoidal dose response curve.

\section{Direct effector functions of MSH-TP15}

First, we analyzed direct effector mechanisms of MSHTP15. MSH-TP15 did not directly inhibit cell proliferation of myeloma cell lines (data not shown), but was capable of inducing apoptosis after antibody cross-linking on the cell surface. MSH-TP15 and rituximab both induced apoptosis in Ramos lymphoma cells expressing ICAM-1 and CD20, while a control IgG1 was not effective (Figure 3A). Total percentage of Annexin $\mathrm{V}$ (AV)-positive cells was calculated by combining early apoptotic $\left(\mathrm{AV}^{+} / 7-\mathrm{AAD}^{-}\right)$and dead cells $\left(A V^{+} / 7-A A D^{+}\right)$as shown for one exemplified experiment in Figure 3B. Next, we analyzed the impact of MSH-TP15 on growth of IL-6-dependent INA-6 myeloma cells in the presence of BMSC isolated from myeloma patients. Growth inhibition of INA-6 cells in these co-culture experiments was observed in the presence of 10 or $100 \mu \mathrm{g} / \mathrm{mL} \mathrm{MSH}$ TP15, while no direct inhibitory effect on growth of BMSC was detectable with $100 \mu \mathrm{g} / \mathrm{mL}$ MSH-TP15 (Figure 3C).

\section{MSH-TP15 Fc-engineered induces natural killer cell killing and macrophage-mediated phagocytosis of myeloma cells}

In order to investigate $\mathrm{Fc}$-mediated effector mechanisms of MSH-TP15, we performed chromium release assays. None of the antibody variants induced complementdependent lysis of myeloma cells (data not shown), but sig- nificant ADCC of plasmocytoma cells could be achieved with MSH-TP15 Fc-eng. and healthy donor's PBMC (Figure 4A). Only minimal lysis was observed with MSHTP15 and as expected no killing was detectable with the Fc k.o. variant and control $\mathrm{mAb}$. $\mathrm{EC}_{50}$ values of $\mathrm{MSH}-\mathrm{TP} 15$ Fc-eng. ranged from $0.36 \mathrm{nM}$ (INA-6) to $3.77 \mathrm{nM}$ (U266) and are summarized in Table 1. Of note, MSH-TP15 Fceng. also induced significant tumor cell lysis when patientderived myeloma cells, including those from relapsed/refractory $\mathrm{MM}$ patients, and purified natural killer (NK) cells were used (Figure 4B, for patient details refer to Table 2). Flow cytometric analyses verified specific binding of MSH-TP15 to the CD138+ tumor cells of all patients (Figure 4B). NK cell induced killing of INA-6 myeloma cells by MSH-TP15 Fc-eng. was additionally investigated with live cell imaging (Figure 4C). Caspase activation and apoptosis of INA-6 cells was present over the entire $24 \mathrm{~h}$ assay time period. Exemplified microscopy images from 0, 6, 12 and $24 \mathrm{~h}$ are shown in Figure 4C. Quantification of the green fluorescent counts (caspasedependent apoptosis) after $24 \mathrm{~h}$ revealed that significant killing of INA-6 myeloma cells occured only in the presence of NK cells and MSH-TP15 Fc-eng. (Figure 4C). Finally, ADCP activity of the MSH-TP15 antibodies was analyzed with Raji lymphoma cells (CD19, CD20 and ICAM-1 positive) and monocyte-derived macrophages 
A

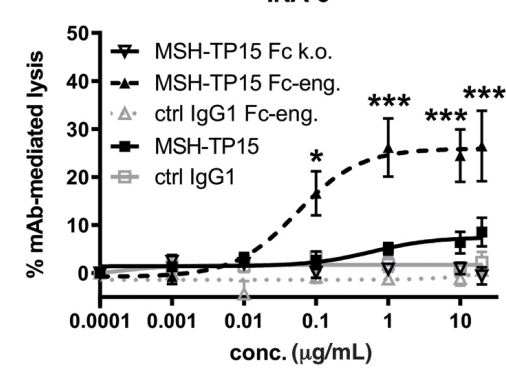

U266

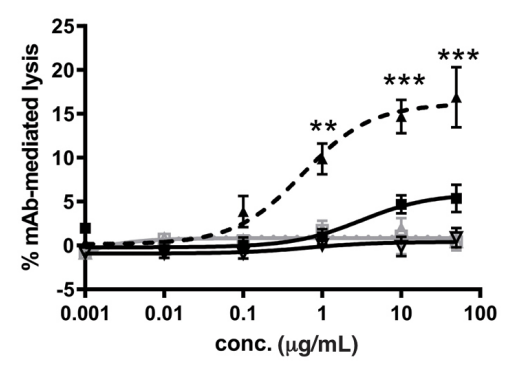

C

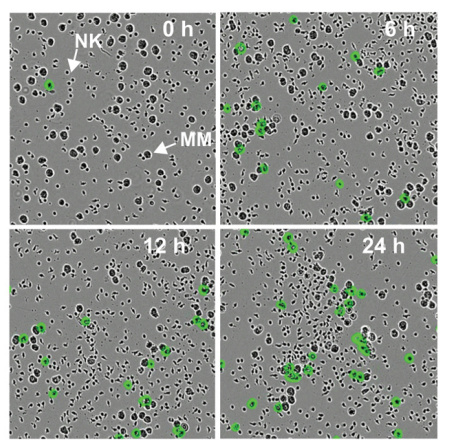

L363

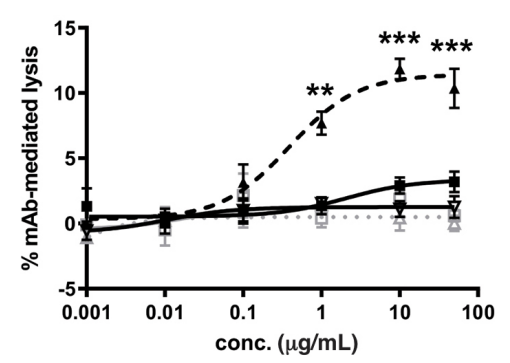

Patients
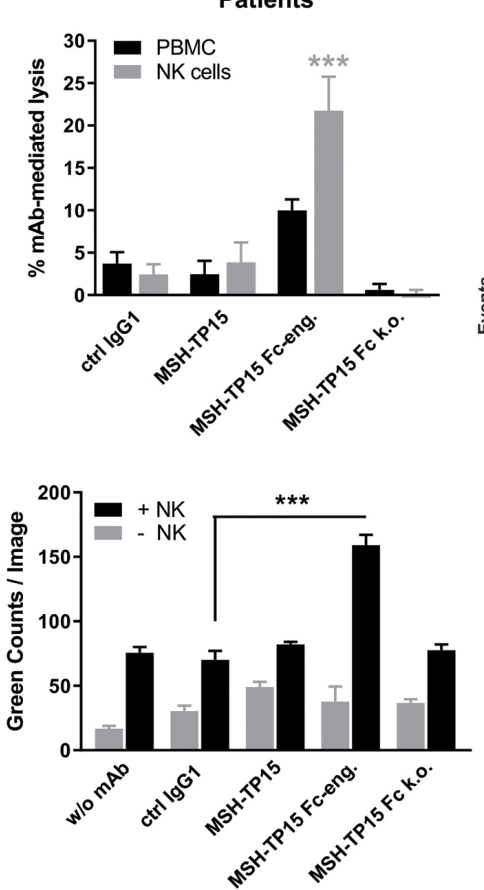

MM1.S

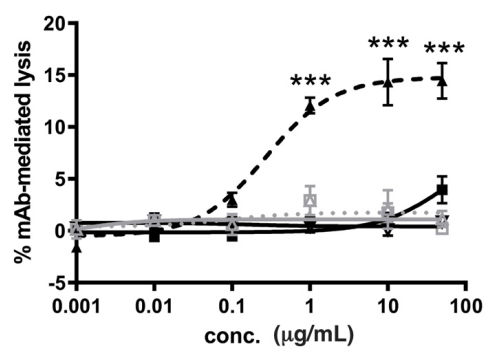

CD138 ${ }^{+}$plasma cells

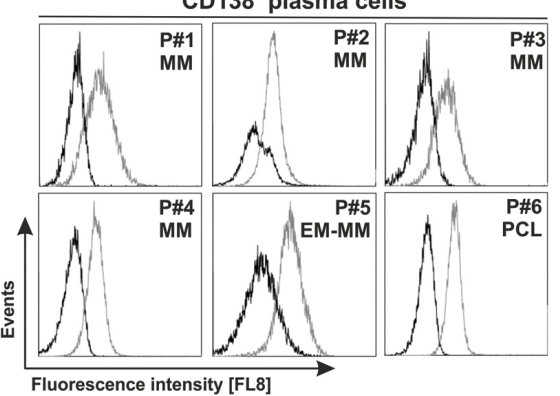

D

ADCP

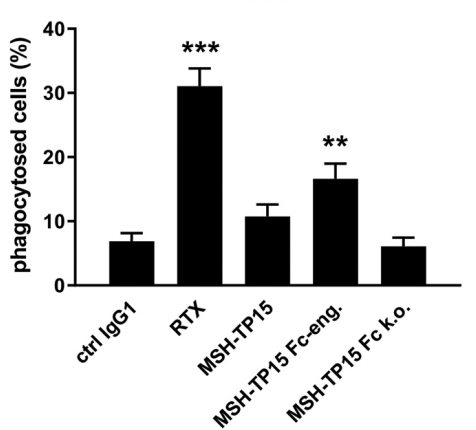

Figure 4. MSH-TP15 Fc-engineered efficiently recruits natural killer cells for antibody-dependent cell-mediated cytotoxicity and engages macrophages for antibodydependent cellular phagocytosis of myeloma and lymphoma cells. (A) Antibody-dependent cell-mediated cytotoxicity (ADCC) experiments were performed as standard 3-hour chromium release assays with increasing antibody concentrations and peripheral blood mononuclear cells (PBMC) of healthy donors at an E:T ratio

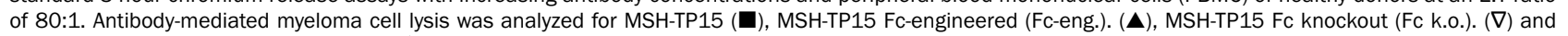
control monoclonal antibodies $(\mathrm{mAb})(\square, \triangle)$ with the indicated cell lines. (B) ADCC experiments with patient-derived tumor cells from BM aspirates of multiple myeloma (MM) patients (P\#1-P\#4), pleural effusion of an extramedullary myeloma (EM-MM) patient (P\#5) and PB of a plasma cell leukemia (PCL) patient (P\#6) were performed with PBMC (80:1; black bars) or natural killer (NK) cells (10:1; grey bars) of healthy donors and $10 \mu \mathrm{g} / \mathrm{mL}$ of the indicated antibodies. Graph shows mean values \pm standard error of the mean of six independent experiments. Histograms on the right show staining of the $\mathrm{CD}_{138^{+}}$malignant plasma cells of these patients (for details please refer to Table 2) with Alexa Fluor 755-labeled MSH-TP15 (grey line) or control (ctrl) IgG1 (black line). (C) Apoptosis of INA-6 myeloma cells was measured by life cell imaging over 24 hours (h). Apoptotic tumor cells became green fluorescent when intracellular caspases were activated. Right graph shows the total green counts/image measured after $24 \mathrm{~h}$ in the presence (black bars) or absence (grey bars) of NK cells and the indicated antibody. Pictures on the left show images taken from start of the experiment $(0 \mathrm{~h}), 6,12$ and $24 \mathrm{~h}$ during incubation of myeloma (MM) and NK cells (NK; E:T ratio 10:1; marked with arrows in the upper left picture) with $20 \mu \mathrm{g} / \mathrm{mL}$ MSH-TP15 Fc-eng. (D) For antibody-dependent cellular phagocytosis (ADCP) analyses macrophages were incubated with $10 \mu \mathrm{g} / \mathrm{ml}$ mAb and Raji lymphoma cells at an E:T ratio of 1:3. Percentage of phagocytosed tumor cells was quantified by flow cytometry gating on CD14 ${ }^{+}$, CFSE ${ }^{+}$and CD19cells. Rituximab (RTX) served as positive control. Experiment was repeated six times with macrophages derived from different donors. Mean values \pm standard error of the mean of phagocytosed tumor cells is summarized in the graph with significant differences between ctrl IgG1 and the other mAb marked with stars. $* * * P<0.001, * * P<0.01$ and $* P<0.05$ of MSH-TP15 mAb/RTX vs. ctrl lgG1 for all experiments.

\section{Table 2. Patient characteristics.}

\begin{tabular}{|c|c|c|c|c|c|}
\hline Patient & Dlagnosis & Sex & Age & Source of material & CD138 ${ }^{+} \mathrm{PC}$ \\
\hline$\# 1$ & MM (IgM), initial diagnosis & $\mathrm{f}$ & $67 y$ & BM, freshly isolated & $30 \%$ \\
\hline \#2 & MM (IgA $\lambda)$, progressive disease & $\mathrm{f}$ & $70 y$ & BM, frozen & $63 \%$ \\
\hline$\# 3$ & MM (IgG), refractory, progress & $\mathrm{m}$ & $56 \mathrm{y}$ & BM, frozen & $58 \%$ \\
\hline \#4 & MM (IgGK) & $\mathrm{m}$ & $54 y$ & BM, freshly isolated & $35 \%$ \\
\hline$\# 5$ & EM-MM (IgG $\lambda$ ), active disease & $\mathrm{f}$ & $70 y$ & PE, freshly isolated & $93 \%$ \\
\hline$\# 6$ & PCL (IgGK), active disease & $\mathrm{f}$ & $67 y$ & $\mathrm{~PB}$, freshly isolated & $80 \%$ \\
\hline
\end{tabular}

MM: multiple myeloma; Ig: immunoglobulin; PC: plasma cell; PCL: plasma cell leukemia; EM: extramedullary; f: female; m: male; y: years; BM: bone marrow; PB: peripheral blood; PE: pleural effusion. 
A

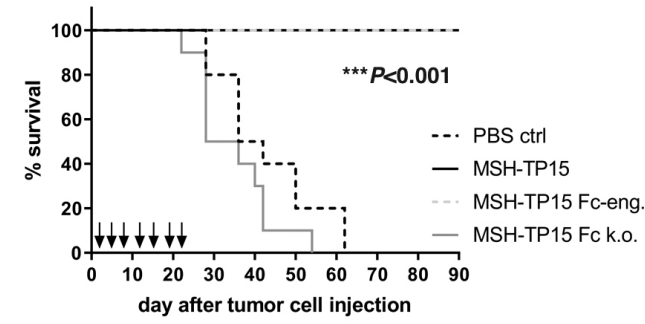

C

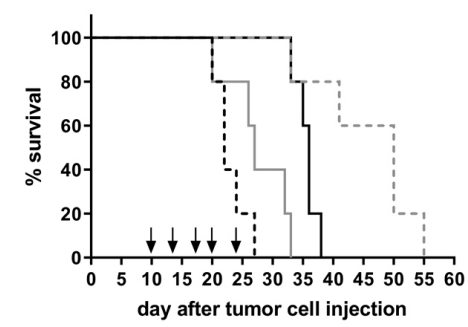

D

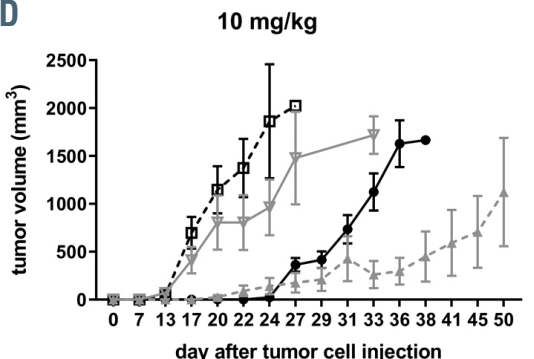

B

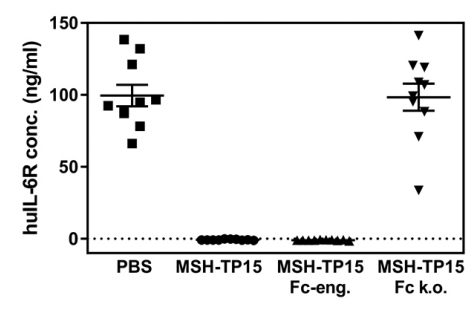

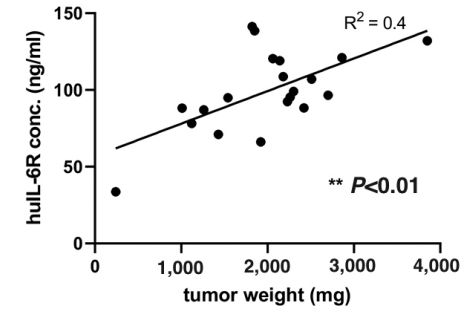

$1 \mathrm{mg} / \mathrm{kg}$
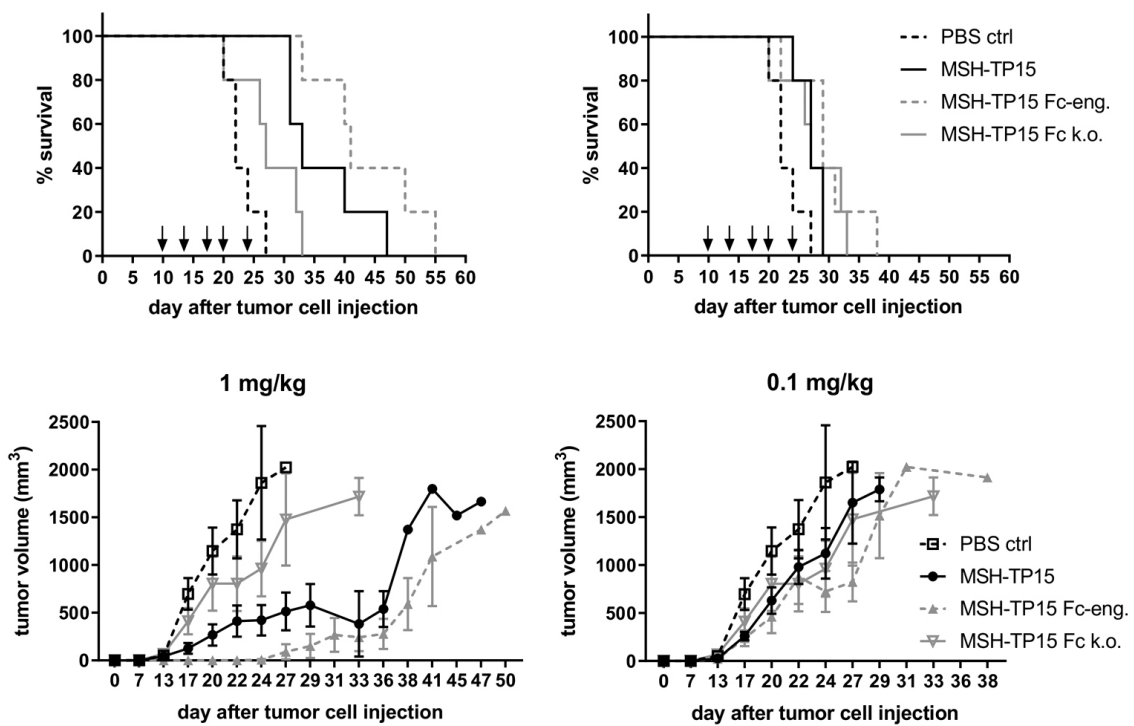

Figure 5. In vivo anti-tumor efficacy of the MSH-TP15 monoclonalantibody variants tested in two myeloma xenograft models. (A) 48 hours (h) after intraperitoneal (i.p.) injection of $2 \times 10^{7}$ INA-6.Tu1_red cells in ten SCID/beige mice per group, animals were treated twice weekly either with vehicle (phosphate buffered saline control [PBS ctrl]; dotted black line), MSH-TP15 (black line), MSH-TP15 Fc-engineered (Fc-eng.) (dotted grey line) or MSH-TP15 Fc knockout (Fc k.o.) (grey line). All mice received one dose of $10 \mathrm{mg} / \mathrm{kg}$ and six doses of $5 \mathrm{mg} / \mathrm{kg}$ by i.p. injection, time points are marked with $\downarrow$. (B) Left graph shows the human interleukin 6 receptor (hulL-6R) concentration in final sera of all mice measured by enzyme-linked immunosorbent assay. Correlation between hulL-6R concentration and tumor weight of the explanted tumors of PBS and MSH-TP15 Fc k.o. treated mice is shown in the right graph. (C) Survival and (D) tumor volume of five mice per group injected subcutaneously with $5 \times 10^{6}$ INA-6.Tu1_red cells 10 days prior start of twice weekly i.p. treatment with five doses of $10 \mathrm{mg} / \mathrm{kg}$ (left graphs), $1 \mathrm{mg} / \mathrm{kg}$ (middle) or 0.1 $\mathrm{mg} / \mathrm{kg}$ (right) MSH-TP15 (black line) and MSH-TP15 Fc-eng. (dotted grey line). Animals in the MSH-TP15 Fc k.o. group (grey line) received 10 mg/kg and PBS treated animals (dotted black line) served as control. $\downarrow$ time point of treatment. Tumor volume was calculated by regular caliper measurement of subcutaneous tumors.

from healthy donors, which highly expressed FcrRII/CD32 and FcrRI/CD64 as well as lower levels of FcrRIIIa/CD16a (Online Supplementary Figure S2). In order to determine $\mathrm{ADCP}, \mathrm{CD} 14$-stained macrophages were incubated with CFSE-labeled Raji cells at an E:T ratio of $1: 3$ in the presence of the indicated $\mathrm{mAb}$. CD14/CFSE double positive and CD19 negative cells were defined as phagocytosed tumor cells by flow cytometry. Significant ADCP activity was observed for MSH-TP15 Fc-eng. and the positive control rituximab, while the MSH-TP15 Fc k.o. completely lacked activity and ADCP by MSH-TP15 was moderate (Figure 4D).

The significant recruitment of $\mathrm{NK}$ cells and macrophages for ADCC and ADCP of myeloma cells by MSH-TP15 Fc-eng. most likely reflects the improved affinity of this variant to FcyRIIIa and FcyRIIa (Figure 1D and E).

\section{MSH-TP15 and MSH-TP15 Fc-engineered have significant in vivo anti-myeloma activity}

The MSH-TP15 mAb variants were tested in INA6.Tu1_red myeloma xenograft models in immunodeficient SCID/beige mice. In the first experiment, $48 \mathrm{~h}$ after i.p. injection of tumor cells treatment with MSH-TP15
$\mathrm{mAb}$ or vehicle control (phosphate buffered saline [PBS]) was started. Within 65 days, control animals and MSHTP15 Fc k.o. treated mice needed to be sacrificed due to tumor size, resulting in a median survival of 39 and 32 days, respectively (Figure 5A). Human IL-6 receptor (huIL6R) secreted by the INA-6.Tu1_red cells was detectable in final sera of these mice and its concentration correlated with explanted tumor weight (Figure 5B). In contrast, animals treated with MSH-TP15 or MSH-TP15 Fc-eng. did not develop any tumors until the end of the experiment on day 90 ( $P<0.001$ vs. control mice) and no huIL-6R was measured (Figure $5 \mathrm{~B}$ ). Thus, treatment with both, $\mathrm{MSH}$ TP15 and MSH-TP15 Fc-eng., completely prevented the development of myeloma in this model.

Next, in order to compare the efficacy of MSH-TP15 and MSH-TP15 Fc-eng. in more detail, doses of 10, 1 or 0.1 $\mathrm{mg} / \mathrm{kg}$ were administered to s.c. tumor bearing mice. MSH-TP15 Fc k.o. was given at $10 \mathrm{mg} / \mathrm{kg}$ and PBS-treated animals served as control (Figure 5C and D). Compared to the control mice that needed to be sacrificed after 22 days, MSH-TP15 Fc k.o. treated mice reached a median survival of 27 days (Figure 5C). Direct, Fab-mediated anti-myeloma effects may account for the slightly delayed tumor 
growth and the survival benefit compared to control mice, but significance was not reached $(P=0.11)$. Of note, treatment with $0.1 \mathrm{mg} / \mathrm{kg}$ MSH-TP15 significantly retarded tumor growth and prolonged survival (27 days; $P=0.03$ vs. control group; Figure 5C and D). Treatment with $1 \mathrm{mg} / \mathrm{kg}$ and $10 \mathrm{mg} / \mathrm{kg}$ further improved tumor control and resulted in a median survival of 33 days and 36 days, respectively $(P<0.01$ for both doses vs. control group). Importantly, with the Fc-optimized MSH-TP15 Fc-eng. survival was not only significantly prolonged compared to PBS-treated animals at doses of $0.1 \mathrm{mg} / \mathrm{kg}$ (29 days, $P=0.02), 1 \mathrm{mg} / \mathrm{kg}$ (41 days, $P<0.01$ ) and $10 \mathrm{mg} / \mathrm{kg}$ (50 days, $P<0.01$ ), but also when compared to $10 \mathrm{mg} / \mathrm{kg}$ MSH-TP15 treated mice $(P=0.03)$. This tendency of being more effective than the wt IgG1 $\mathrm{mAb}$ was also seen at $1 \mathrm{mg} / \mathrm{kg}$ doses, although differences did not reach statistical significance $(P=0.12$; Figure $5 \mathrm{C}$ ). These results point to the importance of efficient effector cell recruitment for the anti-myeloma activity of MSH-TP15 in vivo.

\section{Discussion}

In this study, we characterized the ICAM-1 binding epitope and modes of action of the novel human IgG1 antibody MSH-TP15 originally isolated as scFv antibody by phage display and myeloma cell screening. ${ }^{22}$ Detailed binding analyses revealed that the MSH-TP15 epitope is located at the N-terminal D1-2 of human ICAM-1, which is a trans-membrane glycoprotein that consists of five, heavily glycosylated extracellular Ig domains ${ }^{32}$ The majority of the ICAM-1 ligands bind to D1, including the $\beta 2$-integrin LFA-1 (CD11a/CD18) expressed on all lymphocytes. ${ }^{32}$ ICAM-1 and $\beta 2$-integrin interactions play a pivotal role in lymphocyte activation and adhesion, leukocyte trafficking, and cellular immune responses. In general, ICAM-1 and its ligands are expressed on lymphocytes, leukocytes and vascular endothelium, are increased upon stimulation with inflammatory cytokines like IFN- $\gamma$ and mediate adhesion of immune cells to allow migration into tissue. ${ }^{9}$ Many anti-ICAM-1 antibodies, like RR1/1 and $84 \mathrm{H} 10$, bind to D1 or D2 and inhibit LFA-1-mediated adhesion of lymphocytes to ICAM-1 although they recognize different epitopes. ${ }^{30}$ Our cross-blocking experiments confirmed a unique ICAM-1 epitope recognized by RR1/1 distinct from that of 84H10, MSH-TP15 and BI-505. Potent blockade and thus overlapping epitopes were observed for MSH-TP15 and BI-505, while only partly or no overlapping epitopes were seen for the two human $\mathrm{mAb}$ with $84 \mathrm{H} 10$ and RR1/1. Accordingly, MSH-TP15 was incapable of inhibiting LFA-1 and ICAM-1 interaction. Of note, MSH-TP15 and BI-505 were both identified by phage display and are derived from a fully human scFv library based on the same VH (VH-DP47), but different LC (VL-DPL3 vs. DPK9) framework. ${ }^{22,33}$ This resulted in $89 \%$ $\mathrm{VH}$ sequence identity between the human IgG1 $\mathrm{mAb} \mathrm{BI}$ 505 and the human IgG1к mAb MSH-TP15. Interestingly, in contrast to MSH-TP15, BI-505 was found by screening for apoptosis-inducing antibodies against Ramos Burkitt's lymphoma cells. ${ }^{34}$ Its exact epitope was not determined, but our studies indicate that BI-505 and MSH-TP15 bind close epitopes of human ICAM-1 D1-2.

Despite its important role in immunological processes, ICAM-1 was found to be highly expressed on malignant plasma cells. ${ }^{35,36}$ There ICAM-1 seems to play a pivotal role in myeloma cell adhesion to BMSC, and it is, thus considered to be an important molecule in the tumor-microenvironment and to be essential for immune escape of myeloma cells. In addition, ICAM-1 is thought to be involved in macrophage-induced drug resistance and was shown to be overexpressed on chemo-resistant residual myeloma cells. Furthermore, ICAM-1 expression correlates with tumor progression and metastasis in melanoma and renal cell carcinoma patients, ${ }^{38,39}$ and was recently identified as potential cancer stem cell marker in esophageal squamous cell carcinoma. ${ }^{40}$

Targeting ICAM-1 for therapy was initially evaluated with mouse antibodies that were clinically tested in rheumatoid arthritis, acute stroke and renal transplantation. ${ }^{11-13}$ Production of human anti-mouse Ab caused serious problems after repeated treatment. ${ }^{41,42}$ To date, BI-505 is the only clinically tested human anti-ICAM-1 Ab tested. Of note, repeated administration of $10 \mathrm{mg} / \mathrm{kg}$ BI-505 already saturated ICAM-1 on patient's BM myeloma cells and up to $43 \mathrm{mg} / \mathrm{kg}$ were well tolerated. ${ }^{10,43}$

Many ICAM-1 targeting $\mathrm{mAb}$, including BI-505 and MSH-TP15, exert only little Fab-mediated anti-tumor effects. MSH-TP15 also did not directly affect myeloma cell proliferation, but was capable of inhibiting IL-6dependent INA-6 growth in the presence of BMSC from myeloma patients. This might be an interesting function regarding the supportive role of the BM microenvironment for survival and drug resistance of myeloma cells. Additionally, MSH-TP15 induced apoptosis of ICAM-1 expressing lymphoma cells after cross-linking on the cell surface - a mechanisms which was also described for BI505. ${ }^{6}$ No CDC but moderate ADCP activity and activation of human NK cells for ADCC of myeloma cells was observed for MSH-TP15. Together these data suggest engagement of NK cells and phagocytes as a predominant effector function of MSH-TP15, a fact already evident for scFv-Fc antibody TP15-Fc. ${ }^{22}$ In an attempt to improve the Fc-mediated effector functions of MSH-TP15, we applied Fc protein-engineering. As intended, the DE mutations introduced into the Fc domain of MSH-TP15 Fc-eng. substantially improved the antibody's affinity for FcyRIIIa and FCrRIIa, ${ }^{15,44}$ resulting in enhanced ADCC and ADCP activity of MSH-TP15 Fc-eng. against myeloma cells in vitro. Of note, significant NK cell-mediated tumor cell lysis was also achieved for patient-derived myeloma cells. In vivo, wt and Fc-optimized MSH-TP15 controlled tumor growth in two myeloma xenograft models, while with the k.o. Ab variant no significant survival benefit compared to control mice was achieved. Myeloma cell growth was completely prevented or dose-dependently inhibited by MSH-TP15 and MSH-TP15 Fc-eng. and both antibody variants significantly prolonged survival of the mice. Importantly, improvement in tumor control and survival was also seen in vivo with the Fc-optimized MSHTP15 Fc-eng. compared to MSH-TP15 pointing to an important role of immune cells in mice as well. Due to the fact that in SCDI/bg mice NK cell functions are impaired, most likely mouse myeloid effector cells (monocytes/macrophages, granulocytes) account for the observed differences. This is in line with previous findings that human IgG1 antibodies efficiently bind to mouse FcrRIV, which is the orthologue of human FcyRIIIa, but which is, in contrast to the human system, restricted to mouse myeloid cells and is not expressed on mouse NK cells..$^{45,46}$ Since our novel anti-ICAM-1 antibod- 
ies not only triggered phagocytosis with human macrophages but also significantly triggered ADCC by human NK cells in vitro this might suggest that although in the mouse model myeloid immune effector cells play a dominant role. In patients, together with macrophages also NK cells may constitute a powerful additional effector cell population, which can be recruited for tumor cell killing. Nevertheless, in the subcutaneous model, cure of the mice was not achieved. This leaves room for further improvement and allows testing of combinations of our novel anti-ICAM-1 antibodies with various established anti-myeloma treatment regimen, including proteasome inhibitors, immunomodulatory drugs and chemotherapeutic substances. Systematic testing in our model system may allow the identification of optimal combination partners for potential clinical application.

Taken together, our data indicate that predominantly Fc-mediated effector functions account for the anti-myeloma activity of MSH-TP15 and that by Fc protein-engineering a significant improvement of the antibody's in vitro and in vivo activity was achieved. Particularly for myeloma therapy, where in the post-transplant setting NK cells are among the first immune cells to be present, targeting resid- ual tumor cells in the patients BM with an Fc-eng. antiICAM-1 antibody like MSH-TP15 Fc-eng. might be a promising strategy to improve clinical outcome.

\section{Disclosures}

No conflicts of interest to disclose.

\section{Contributions}

$K K, M C, C K, T R, A O, S K$ and $A L$ performed the research; $K K$ and MP wrote the manuscript; $C K, F N, T R, T V$ and $M G$ contributed to writing of the manuscript; $M G$ and MP supervised the study

\section{Acknowledgments}

The authors would like to thank Kathrin Richter, Jan Brdon, Britta von Below and Anja Muskulus for excellent technical assistance.

\section{Funding}

This study was supported by a research grant from the Deutsche Krebshilfe e.V. (Mildred-Scheel-Professorship program) to MP and Else Kröner-Fresenius-Stiftung (2015_A166) to $K K$.

\section{References}

1. Jakubowiak A, Offidani M, Pegourie B, et al. Randomized phase 2 study: elotuzumab plus bortezomib/dexamethasone vs bortezomib/dexamethasone for relapsed/refractory MM. Blood. 2016;127(23):2833-2840.

2. Nijhof IS, Casneuf T, van Velzen J, et al. CD38 expression and complement inhibitors affect response and resistance to daratumumab therapy in myeloma. Blood. 2016;128(7):959-970.

3. Markovina S, Callander NS, O'Connor SL, et al. Bone marrow stromal cells from multiple myeloma patients uniquely induce bortezomib resistant NF-kappaB activity in myeloma cells. Mol Cancer. 2010;9:176.

4. Meads MB, Gatenby RA, Dalton WS. Environment-mediated drug resistance: a major contributor to minimal residual disease. Nat Rev Cancer. 2009;9(9):665-674.

5. Kawano Y, Moschetta M, Manier S, et al. Targeting the bone marrow microenvironment in multiple myeloma. Immunol Rev. 2015;263(1):160-172

6. Veitonmaki N, Hansson M, Zhan F, et al. A human ICAM-1 antibody isolated by a function-first approach has potent macrophage-dependent antimyeloma activity in vivo. Cancer Cell. 2013; 23(4):502-515.

7. Schmidmaier R, Morsdorf K, Baumann P, Emmerich B, Meinhardt G. Evidence for cell adhesion-mediated drug resistance of multiple myeloma cells in vivo. Int J Biol Markers. 2006;21(4):218-222.

8. Zheng Y, Yang J, Qian J, et al. PSGL$1 /$ selectin and ICAM-1/CD18 interactions are involved in macrophage-induced drug resistance in myeloma. Leukemia. 2013;27(3):702-710.

9. Dustin ML, Rothlein R, Bhan AK, Dinarello CA, Springer TA. Induction by IL 1 and interferon-gamma: tissue distribution, biochemistry, and function of a natural adherence molecule (ICAM-1). J Immunol. 1986;137(1):245-254

10. Hansson M, Gimsing P, Badros A, et al. A
Phase I dose-escalation study of antibody BI-505 in relapsed/refractory multiple myeloma. Clin Cancer Res. 2015; 21(12):2730-2736

11. Haug CE, Colvin RB, Delmonico FL, et al. A phase I trial of immunosuppression with anti-ICAM-1 (CD54) mAb in renal allograft recipients. Transplantation. 1993;55(4):766773 .

12. Kavanaugh AF, Davis LS, Jain RI, et al. A phase I/II open label study of the safety and efficacy of an anti-ICAM-1 (intercellular adhesion molecule-1; CD54) monoclonal antibody in early rheumatoid arthritis. J Rheumatol. 1996;23(8):1338-1344.

13. Schneider D, Berrouschot I, Brandt T, et al. Safety, pharmacokinetics and biological activity of enlimomab (anti-ICAM-1 antibody): an open-label, dose escalation study in patients hospitalized for acute stroke. Eur Neurol. 1998;40(2):78-83.

14. Scott AM, Wolchok JD, Old LJ. Antibody therapy of cancer. Nat Rev Cancer. 2012;12(4):278-287.

15. Lazar GA, Dang W, Karki S, et al Engineered antibody Fc variants with enhanced effector function. Proc Natl Acad Sci U S A. 2006;103(11):4005-4010.

16. Moore GL, Chen H, Karki S, Lazar GA. Engineered FC variant antibodies with enhanced ability to recruit complement and mediate effector functions. MAbs. 2010;2(2):181-189.

17. Richards JO, Karki S, Lazar GA et al. Optimization of antibody binding to FcrRIIa enhances macrophage phagocytosis of tumor cells. Mol Cancer Ther. 2008; 7(8):2517-2527.

18. de Jong RN, Beurskens FJ, Verploegen S, et al. A novel platform for the potentiation of therapeutic antibodies based on antigendependent formation of $\operatorname{IgG}$ hexamers at the cell surface. PLoS Biol. 2016;14(1): e1002344.

19. Kellner C, Otte A, Cappuzzello E, Klausz K, Peipp M. Modulating cytotoxic effector functions by Fc engineering to improve cancer therapy. Transfus Med Hemother.
2017;44(5):327-336.

20. Jurczak W, Zinzani PL, Gaidano G, et al. Phase Ila study of the CD19 antibody MOR208 in patients with relapsed or refractory B-cell non-Hodgkin's lymphoma. Ann Oncol. 2018;29(5):1266 1272.

21. Bang YJ, Giaccone G, Im SA, et al. First-inhuman phase 1 study of margetuximab (MGAH22), an Fc-modified chimeric monoclonal antibody, in patients with HER2positive advanced solid tumors. Ann Oncol. 2017;28(4):855-861.

22. Klausz K, Cieker M, Kellner C, et al. A novel Fc-engineered human ICAM-1/CD54 antibody with potent anti-myeloma activity developed by cellular panning of phage display libraries. Oncotarget. 2017 8(44):77552-77566

23. Peipp M, Lammerts van Bueren JJ, Schneider-Merck T, et al. Antibody fucosylation differentially impacts cytotoxicity mediated by $\mathrm{NK}$ and PMN effector cells. Blood. 2008;112(6):2390-2399.

24. Lux A, Yu X, Scanlan CN, Nimmerjahn F Impact of immune complex size and glycosylation on $\operatorname{IgG}$ binding to human FcgammaRs. J Immunol. 2013;190(8):43154323

25. Burger R, Guenther A, Bakker F, et al. Gp130 and ras mediated signaling in human plasma cell line INA-6: a cytokineregulated tumor model for plasmacytoma. Hematol J. 2001;2(1):42-53.

26. Glorius P, Baerenwaldt A, Kellner C, et al The novel tribody [(CD20)(2)xCD16] efficiently triggers effector cell-mediated lysis of malignant B cells. Leukemia. 2013; 27(1):190-201.

27. Hansson MFB, inventor; The use of antibodies against ICAM-1 in the treatment of patients with relapsed cancer. 2012 Intl. Cl. C07K 16/28 (2006.01). Appl. No.: PCT/EP2011/061983

28. Kellner C, Derer S, Klausz K, et al. Fc glycoand Fc orotein-engineering: design of antibody variants with improved ADCC and CDC activity. Methods Mol Biol. 2018; 
1827:381-397.

29. Staudinger M, Glorius $P$, Burger R, et al. The novel immunotoxin HM1.24-ETA' induces apoptosis in multiple myeloma cells. Blood Cancer J. 2014;4:e219.

30. Makgoba MW, Sanders ME, Ginther Luce GE, et al. A cluster of antibodies (RR1/1, LB-2 and 84H10) that inhibit LFA-1-dependent lymphoid and myeloid cell adhesion bind intercellular adhesion molecule-1 (ICAM-1). In: Dupont B, editor. Immunobiology of HLA. Vol II. Berlin: Springer-Verlag New York; 1989.

31. Rothlein R, Dustin ML, Marlin SD, Springer TA. A human intercellular adhesion molecule (ICAM-1) distinct from LFA-1. J Immunol. 1986;137(4):1270-1274.

32. Staunton DE, Marlin SD, Stratowa C, Dustin ML, Springer TA. Primary structure of ICAM-1 demonstrates interaction between members of the immunoglobulin and integrin supergene families. Cell. 1988; 52(6):925-933.

33. Soderlind E, Strandberg L, Jirholt P, et al. Recombining germline-derived CDR sequences for creating diverse single-framework antibody libraries. Nat Biotechnol. 2000;18(8):852-856.

34. Fransson J, Tornberg UC, Borrebaeck CA, Carlsson R, Frendeus B. Rapid induction of apoptosis in B-cell lymphoma by functionally isolated human antibodies. Int J Cancer. 2006;119(2):349-358.
35. Tatsumi T, Shimazaki C, Goto $\mathrm{H}$, et al. Expression of adhesion molecules on myeloma cells. Jpn J Cancer Res. 1996;87(8):837-842.

36. Van Riet I, De Waele M, Remels L, et al. Expression of cytoadhesion molecules (CD56, CD54, CD18 and CD29) by myeloma plasma cells. Br J Haematol. 1991; 79(3):421-427.

37. Paiva B, Corchete LA, Vidriales MB, et al. Phenotypic and genomic analysis of multiple myeloma minimal residual disease tumor cells: a new model to understand chemoresistance. Blood. 2016;127(15): 1896-1906.

38. Galore-Haskel G, Baruch EN, Berg AL, et al. Histopathological expression analysis of intercellular adhesion molecule 1 (ICAM-1) along development and progression of human melanoma. Oncotarget. 2017; 8(59):99580-99586.

39. Juengel E, Krueger G, Rutz J, et al. Renal cell carcinoma alters endothelial receptor expression responsible for leukocyte adhesion. Oncotarget. 2016;7(15):20410-20424.

40. Tsai ST, Wang PJ, Liou NJ, et al. ICAM1 is a potential cancer stem cell marker of esophageal squamous cell carcinoma. PLoS One. 2015;10(11):e0142834.

41. Kavanaugh AF, Schulze-Koops H, Davis LS, Lipsky PE. Repeat treatment of rheumatoid arthritis patients with a murine anti-intercellular adhesion molecule 1 monoclonal antibody. Arthritis Rheum. 1997;40(5):849853.

42. Furuya K, Takeda H, Azhar S, et al Examination of several potential mechanisms for the negative outcome in a clinical stroke trial of enlimomab, a murine antihuman intercellular adhesion molecule-1 antibody: a bedside-to-bench study. Stroke. 2001;32(11):2665-2674.

43. Wichert S, Juliusson G, Johansson A, et al A single-arm, open-label, phase 2 clinical trial evaluating disease response following treatment with BI-505, a human anti-intercellular adhesion molecule-1 monoclonal antibody, in patients with smoldering multiple myeloma. PLoS One. 2017; 12(2): $\mathrm{e} 0171205$

44. Hamaguchi Y, Xiu Y, Komura K, Nimmerjahn F, Tedder TF. Antibody isotype-specific engagement of Fcy receptors regulates B lymphocyte depletion during CD20 immunotherapy. J Exp Med. 2006; 203(3):743-753

45. Kerntke C, Nimmerjahn F, Biburger M There Is (Scientific) Strength in numbers: a comprehensive quantitation of $\mathrm{F} c \gamma$ receptor numbers on human and murine peripheral Blood Leukocytes. Front Immunol. 2020; 11:118.

46. Lux A, Nimmerjahn F. Of mice and men: the need for humanized mouse models to study human IgG activity in vivo. J Clin Immunol. 2013;33(Suppl 1):S4-8. 